\title{
Conhecimento e competência
}

Paula Broeiro*

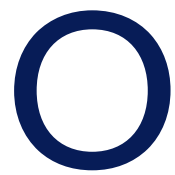

conhecimento é um "activo", um "capital" ou um "bem". Constitui actualmente um recurso valioso e insubstituível enquanto força motriz organizacional. ${ }^{1}$ Em contextos, cada vez mais, incertos e imprevisíveis e onde mercados, produtos, tecnologia e sociedade se transformam a um ritmo acelerado, o conhecimento tem assumido uma vantagem competitiva sustentável. ${ }^{1-2}$ É neste ambiente que emerge a relevância do conceito de gestão do conhecimento. ${ }^{1-2} \mathrm{O}$ conhecimento e a sua estruturação, tal como as aptidões, têm variabilidade individual, isto é, pessoas diferentes incorporam a informação de forma diferente e constroem os seus conhecimentos de acordo com as suas experiências e quadros de referências. ${ }^{3}$

Em medicina, o conhecimento, por si só, não assegura a competência clínica, como se demonstra pelo número de médicos certificados e recertificados pelo American Board of Family Practice que mantêm resultados clínicos fracos. ${ }^{4}$

Competência significa um conjunto de conhecimentos, aptidões, atitudes e qualidades pessoais essenciais à prática de uma profissão específica ${ }^{5} \mathrm{Com}$ a actualização da informação, a par da experiência adquirida, o conhecimento evolui e torna-se complexo. Isto é, deixa de ser apenas saber (conhecimento), incorporando outras dimensões como saber fazer, saber ser, ${ }^{6}$ saber pensar e saber integrar. Evolui-se de um pensamento linear para um pensamento complexo e do conhecimento para a competência, num processo cíclico e gradual em espiral, de regresso aos mesmos temas com maturidade e/ou profundidade diferentes. $\mathrm{O}$ desenvolvimento de conhecimentos e competências, desde a competência cognitiva, funcional, social, ética à metacompetência, fica alinhado com as fases de progressão profissional. ${ }^{5}$

Em todas as profissões, incluindo as da saúde, deve ser definido o perfil de competências profissionais es-

* Directora da Revista Portuguesa de Medicina Geral e Familiar senciais ou nucleares ${ }^{7}$ críticas, as estratégicas que todos devem cumprir. Todas as competências, nucleares e críticas, são adquiridas por modelagem e avaliação. A modelagem identifica as competências e a avaliação determina em que medida os indivíduos adquiriram essas competências ${ }^{6} \mathrm{e}$ se, integradas num processo de feedback construtivo, permitem melhorar a prática. ${ }^{8} \mathrm{~A}$ competência em medicina é definida como o uso regular e criterioso: da comunicação, conhecimento, aptidões técnicas, raciocínio clínico, emoções, valores e reflexão sobre prática para benefício dos indivíduos e comunidades. ${ }^{5}$

Em Portugal, a formação pós-graduada foi, desde o seu início, desenvolvida em contexto de exercício real. Com a definição, aprovação e publicação dos programas de formação das diferentes especialidades foi tornada obrigatória a explicitação dos objectivos de conhecimento e dos objectivos de desempenho (competências). Em simultâneo, o processo de avaliação de desempenho em internato, independentemente da área de especialização, passou a reflectir os domínios de competência: cognitivo, funcional, ético, pessoal e relacional (capacidade de execução técnica, interesse pela valorização profissional, responsabilidade profissional e relações humanas no trabalho) ${ }^{9}$

A aprendizagem ao longo da vida e a avaliação desempenham um papel integrante do processo de identificação e resposta dos próprios médicos às necessidades educacionais. ${ }^{8}$ É, pois, contextual a competência e reflecte a relação entre capacidades individuais e tarefas/necessidades reais do lugar de prática. ${ }^{8}$ Por isso, as características da prática, ${ }^{7}$ da carga local de doença e sociodemográficas condicionam o processo de aquisição de competências, sendo indispensável a selecção criteriosa das situações a que devem ser expostos alunos ou médicos em formação. Existem aspectos de competência, como anamnese e raciocínio clínico, cujos conteúdos específicos nem sempre são generalizáveis. ${ }^{8}$ Por exemplo, quanto ao raciocínio clínico, um médico pode ser competente em áreas em que tem uma 
base sólida de conhecimento (organizado e acessível) e menos competente em áreas de menor conhecimento, enquanto o domínio da relação médico-doente está menos dependente do conteúdo da situação de treino, mas altamente dependente da sua frequência (variabilidade) e das competências pessoais. ${ }^{8}$ Competência depende do desenvolvimento do pensamento, comportamentos, atitudes e da reflexão sobre a experiência real, dela extraindo regras práticas ${ }^{8}$ (e.g., passos da consulta ou princípios do método clínico centrado no paciente).

O Canadá, tal como Portugal, não formou um número suficiente de médicos ${ }^{10-11}$ para responder às necessidades do seu crescimento, do envelhecimento e da dispersão populacional. ${ }^{11}$ Desde Junho de 2009, o Colégio de Médicos de Família do Canadá (CFPC) propôs uma formação pós-graduada que continuasse credível, com visão de futuro e que atendesse às necessidades das comunidades, adaptável a novas exigências de saúde, da sociedade e dos sistemas. ${ }^{11} \mathrm{O}$ currículo baseia-se em três competências críticas, que designaram Triple $C$ (figura 1), dando ênfase à abrangência (comprehensive), continuidade e centrado nos pacientes e famílias. ${ }^{11} \mathrm{O}$ objectivo primordial é preparar novos médicos de família para o desempenho clínico efectivo ao longo das próximas décadas. ${ }^{11}$

O que significa desempenho clínico efectivo? Significa mais do que a revisão simplista de registo do paciente $^{4}$ ou do cumprimento de indicadores de gestão. ${ }^{12}$ O desempenho clínico efectivo deverá ser suportado por competências que produzam melhorias sustentáveis nos cuidados ao paciente. ${ }^{4}$ Deverá, pois, estar integrado num sentido de coerência individual e organizacional, ${ }^{13}$ em que os vários domínios de competência sejam avaliados de forma integrada, coerente e longitudinal, usando métodos de feedback construtivo. ${ }^{8}$

Uma tipologia holística de competências é útil à compreensão da associação entre conhecimentos, aptidões e atitudes, indispensáveis à integração das competências aplicadas: conceptual (cognitiva, conhecimento e compreensão) e operacional (funcional, psicomotor e de qualificação). As competências, associadas à auto-eficácia, são de natureza conceptual (meta-competência, incluindo aprender a aprender) e operacional (competência social, incluindo comportamentos e atitudes) ${ }^{6}$

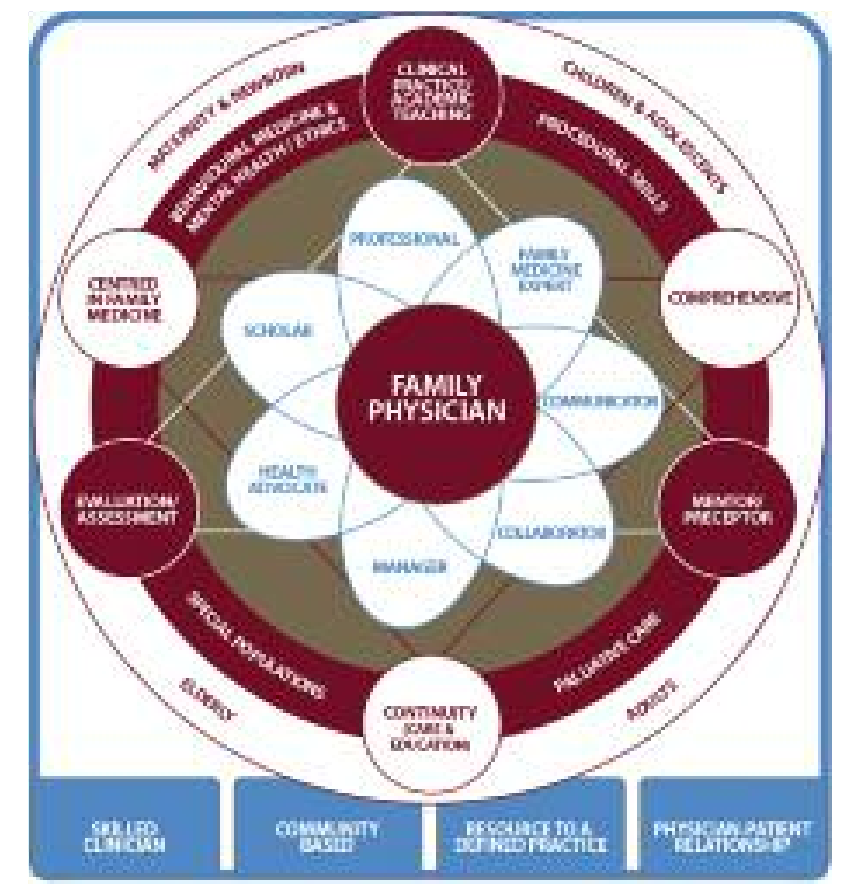

Figura 1. Representação gráfica do programa Canadiano Triple $C^{11 *}$.

A academia, para se adaptar aos contextos de mudança, tem, ela própria, o desafio de desenvolver competências investigacionais, educacionais e de cuidado aos pacientes. Deverá promover o desenvolvimento de um quadro coerente de competências que permita a sua organização e que possa ser aplicado em todos os estadios formativos, desde o pré-graduado até à formação ao longo da vida, clarificando o que se pretende atingir em cada uma dessas fases. ${ }^{5}$

O sucesso organizacional, bem como a eficiência dos sistemas de saúde, só se conseguirá se existir uma clara definição do perfil de competências de cada profissão, numa complementaridade de funções centradas nas necessidades dos indivíduos, doentes ou não. É no espelhar da vida e obra do Prof. José Guilherme Jordão, na sua coerência, no seu sentido de visão estratégica, espirito de missão, cultura e humanismo ${ }^{14}$ que se apela ao sentido crítico individual e colectivo da Medicina Geral e Familiar Portuguesa. ${ }^{15}$

*Figura publicada com autorização. 


\section{REFERÊNCIAS BIBLIOGRÁFICAS}

1. Cardoso L. Gestão do conhecimento e competitividade organizacional: um modelo estrutural. Comport Organ e Gestão. 2007;13(2):191-211. Portuguese

2. Al-Hawamdeh S. Knowledge management: re-thingking information management and facing the challenge of managing tacit knowledge. Inform Res. 2002;8(1):paper143.

3. Pusic MV, Kessler D, Szyld D, Kalet A, Pecaric M, Boutis K. Experience curves as an organizing framework for deliberate practice in emergency medicine learning. Acad Emerg Med. 2012;19(12):1476-80.

4. Lainhart N, Hagen MD. The evolution of maintenance of Certification for Family Physicians (MC-FP) Part IV, Performance and Practice. Ann Fam Med. 2014;12(4):384-5.

5. Milner RJ, Gusic ME, Thorndyke LE. Perspective: toward a competency framework for faculty. Acad Med. 2011;86(10):1204-10.

6. Le Deist FD, Winterton J. What is competence? Hum Resour Dev Int. 2005;8(1):27-46.

7. Heyrman J, editor. The EURACT educational agenda. Lisboa:Associação Portuguesa de Medicina Geral e Familiar; 2006.

8. Epstein RM. Assessment in medical education. N Engl J Med. 2007;356(20):387-96.
9. Portaria n²51/2011, de 24 de Junho. Diário da República. 1a série (120).

10. Santana P, Peixoto $H$, Duarte $N$. Demografia médica em Portugal: análise prospetiva [Demography of physicians in Portugal: prospective analysis]. Acta Med Port. 2014;27(2):246-51. Portuguese

11. Tannenbaum D, Kerr J, Konkin J, Organek A, Parsons E, Saucier D, et al. Triple C competency-based curriculum: report of the Working Group on Postgraduate Curriculum Review - Part 1. Mississauga, ON: College of Family Physicians of Canada; 2011.

12. Braga R. Os indicadores de saúde e a contratualização. Rev Port Med Geral Fam. 2013;29(5):278-80. Portuguese

13. Barroso R, Fernandes A, Moeda A, Boavida H, Pisco AM, Desterro A, et al. Olhares [Internet]. Évora: CIMGFSUL; 2013. Available from: http://www.cimgfsul.org/images/fim/olhares.pdf

14. Alves MV. José Guilherme Jordão: uma vida e uma obra para o futuro. Rev Port Med Ger Fam. 2015;31(2):90-2. Portuguese

15. Broeiro P. Papel social do pensamento crítico. Rev Port Med Geral Fam. 2014;30(3):147-8. Portuguese

\section{ENDEREÇO PARA CORRESPONDÊNCIA}

director@rpmgf.pt 